Trefry, John H., Laurel B. Watson. "The Silenced Voices of Architectural Discourse: Promoting Inclusion Through Qualitative Research." Enquiry 10.1 (2013) 4-13.

\section{The Silenced Voices of Architectural Discourse: Promoting Inclusion Through Qualitative Research}

\author{
John H. Trefry \\ Laurel B. Watson
}

ten thousand different sounds, ten thousand chances to touch and smell the place intimately? We recognize that both answers should be correct, though because of the way discourse is framed, the balance is currently tipped toward the institutionally knighted scholar.

The majority of scholarly research in architecture employs a shared institutional voice. This voice excludes non-authoritative perspectives to centralize control over the dominant narratives of the field. In architectural education this mode of discourse supports a positivist, or objectively determined, function of architecture in society. Instead, a more open, constructionist model, in which the inhabitants of the built world participate in making meaning and distinguishing value might be more congruent. As much as those in architectural practice recognize the positivist model is unrealistic, as a professional ethos it is virtually inescapable. Its roots in the system of education go deep into the fundamental language of discourse.

We are not innocent from adopting the institutional voice in this article. The grip of convention in architectural scholarship is tenacious. We use this work to advocate for qualitative research, a method born in the social sciences, as a productive antidote to the exclusionary voice of institutional scholarship. The choice to apply qualitative research methods is predicated on the ontological assumption that reality is subjective and multiple, not monolithic. Although this assumption is acknowledged in much contemporary architectural scholarship, the institutional voice hampers full commitment to the idea. Qualitative research is inductive. It approaches meaning through the content of multiple voices rather than the deductive reasoning of a homogenous voice. The type of knowledge qualitative research would foster in the architectural community is counter to the latent positivism of institutional writing. We agree with Audre Lorde's adage that "the master's tools will never dismantle the master's house" (Lorde, 110-114).

This article first explores the voice of academic architectural discourse through journal publication trends, the accreditation criteria of the National Architectural Accreditation Board (NAAB), and the current application of qualitative research to architecture. We then compare this to the actual contemporary needs and expectations of the profession, as enumerated by the American Institute of Architects (AIA) to gauge whether the voice of discourse is currently serving the profession. Finally we develop a better understanding of qualitative research in the social 
sciences and how its application might participate in bridging the gap between academic discourse and professional application.

\subsection{THE ROLE OF ACADEMIC INSTITUTIONS IN EXCLUDING ADDITIONAL VOICES FROM ARCHITECTURAL DISCOURSE}

\subsection{The institutional voice of architectural discourse}

The institutional voice of architectural scholarship is characterized by authoritative detachment and a preponderance of citations, references, and quotations. These are tactics that distinguish academic writing from most other prose. Although no intellectual endeavor can begin without a foundation of preexisting knowledge, the use of previously published and vetted sources of knowledge results in a monolithic perspective. This has three inextricable effects: to fragment and subdue the author's personal voice, to reinforce the hegemony of institutional knowledge, and to limit the access of additional voices into the discourse. Individual scholars perpetuate institutional hegemony. Institutional authority is upheld by restricting the inclusion of additional voices to the discourse of architecture.

Through its incestuous validation of information, the institutional voice structurally and psychologically isolates the meaning and value of architecture within the profession. This reinforces the damaging myth of architects as heroes and the resultant exclusion of the public from the discourse of the profession. More insidiously, this myth is passed on to the students who retain these undercurrents in practice. The academic institution, the source of architect's education, preserves the myth. Because architectural scholarship provides the language of academic discourse, the cycle of this myth's ratification remains unbroken in the emerging ranks of the profession.

Institutionally-backed writing has a major role as a gatekeeper of the information, positions, and voices that establish the dominant narrative for contemporary practices. Because scholars trade in the overwhelming complexity of their contemporaneous contexts, it often becomes convenient to simplify and subdue complex origins and trajectories (Alloway, 244). Although this may be a casual act in the composition of a piece of writing, the force of institutional ratification behind such dismissals has a precipitating effect in literature and on student populations. Art critic and curator Lawrence Alloway called these "spectacular acts of exclusion" (Alloway, 243). They participate with the institutional voice to effectively silence the complex present that myriad voices, professional and untrained, shape and occupy.

\subsection{The impact of academic journals on architectural discourse}

Academic institutions define the intellectual agenda of young architects headed into practice. Scholarly journals play the preeminent role in establishing the concepts and language employed in the discourse of architecture those academic institutions. As a central component of the educational climate, journals affect and shape the positions and perspectives of students who will go into practice constructing the built environment. They also play a key role in the promotion of departments and programs for admissions and recruiting, fundraising, and general cachet. Further, because of its institutional legitimacy, journal research is able to influence policy decisions related to the field (Crysler, 9-10).

The tone and conceptual framework of contemporary architectural journals seems to take note of this power dynamic. Assemblage, founded as a reaction against discourse that "maintains disciplinary boundaries, dominant institutions, and disengaged modes of practice" (Crysler, 58). Assemblage worked to reject the idea that meaning is inherent in the architectural object and to embrace the author's subjective power. By utilizing concepts and texts from a variety of disciplines their goal was to move architectural knowledge outside of architecture proper into the general socio-cultural field. Architectural objects were approached obliquely hoping to dislodge the static narrative of their cultural context. Though acknowledging the social construction of architecture's value and meaning inherently in its project, Assemblage continued to use institutionally ratified texts as the source of its wellspring of its subjective meaning.

The final issue of Assemblage was published in 2000. Anumber of journals have continued its transcoding project of integrating architectural content with diverse sources from art, literature, current events, sociology, and popular culture, to name a few. These journals are primarily the product of colleges of architecture. MIT's Grey Room has been published since 2000. From its introductory issue mission statement, it takes the mantle of Assemblage by dedicating itself "to the theorization of modern and contemporary architecture, art, media, and politics" (Alexander, et al, 5). Here, too, are references to instability and subjectivity:

Grey Room will act to cultivate scholarly discussions in which contemporary and historical events, objects, and configurations are cast as unstable, even volatile, participants in a high-stakes struggle where disciplinary practices and discursive matrices meet, and where the terms on which aesthetics, politics, and technologies intersect and are contested. (Alexander, et al, 5)

Yet again the texts published under this manifesto employ the detached, univocal voice that asserts objectivity through its reliance on stable structures of institutional power.

Assemblage's interdisciplinary project had a profound influence on the character of contemporary architectural scholarship and practice. New resources from cinema, to philosophy, to popular culture found their way into the discourse of the field. But did the voice of Assemblage and its progeny really differ in a material way from those they reacted against? The reliance on, and necessity of, the social world to actualize and make meaning of form are paid lip-service through the assertion that the texts 
are architectural conditions whose meaning is constructed outside of their form. However, by refusing to fully reject the institutional cycle of affirmations, this postmodern sleight of hand continues to serve the goal of ossifying institutional authority. The plurality of voices is a chorus of the powerful in a variety of disciplines rather than the society who privately make its own meaning from experiences in the built world. The concern is not whether the diverse products of institutional hegemony are complex enough to represent architecture's plurality. The work of Assemblage and others more than proves they are up to the task. However, for contemporary architectural discourse to acknowledge architecture as a social phenomenon while artificially addressing its complexity in terms of the language of the institution, rather than the language of the society that activates it, is a missed opportunity. We don't argue against the legitimacy of scholarship originating in institutions. However, we do argue that they have greater responsibility to the citizens of the built world to be more inclusive in their inquiries.

\subsection{The National Architectural Accreditation Board and the spirit of architectural education}

Journals may play the preeminent role in establishing the language used to discuss architecture in the academic setting, but other mechanisms are in place to control the content and aspirations of that language. NAAB describes itself as the leading organization for establishing "educational quality assurance standards to enhance the value, relevance, and effectiveness of the architectural profession" (NAAB 2009 , 4). The majority of NAAB's board members are practitioners rather than educators. Thus, the standards published in NAAB's Accreditation Conditions represent the profession's expectations of its educational system. Most recently published in 2009, the Accreditation Conditions were reevaluated in a July 2013 meeting and an update is due to be released in 2014.

The "Student Performance Criteria" in the Accreditation Conditions are subdivided into three realms: (A) Critical Thinking and Representation, (B) Integrated Building Practices, Technical Skills and Knowledge, and (C) Leadership and Practice (NAAB 2009, 21-25). We focus on realms $A$ and $C$ for brevity, but posit that such attitudes represented in more inclusive scholarly discourse might still be applicable to realm B. Each realm contains areas of proficiency called "criteria." Though some of these criteria could be characterized as directly related to the technical practicalities of building production, many are more related to the larger integration of buildings in the public realm. These are of particular interest to this article.

Realm A contains such criteria as the understanding cultural factors, diverse points of view, diverse values and physical abilities, and the impact of applied research on human conditions. Realm $\mathrm{C}$ contains such criteria as the understanding the relationship of the natural and built world to human behavior, understanding the needs of the client, how to work collaboratively on community-centered issues, understanding how to work in the public interest to improve quality of life (NAAB 2009, 21-25).

Additionally, the Accreditation Conditions identify each criterion as one of two forms of accomplishment: "ability" or "understanding." NAAB characterizes "ability" criteria with language that connotes didactic rigidity such as "proficiency," "specific", "correct", "appropriate", and "accurate." These criteria are predicated on the notion that there are "correct," "appropriate," and "accurate" aspects of architecture. Conversely, the "understanding" criteria are defined by "the capacity to classify, compare, summarize, explain and/or interpret information" (NAAB 2009, 21). This mode of learning relies on a more subjective model of knowledge than the positivist "ability" criteria. Criteria categorized as "understanding" account for more than half of all criteria. All of those listed in the above paragraph are "understanding" accomplishments. It is implied in the Accreditation Conditions that "ability" is more difficult for a student to achieve than "understanding." Describing changes found in the 2009 publication, the level of achievement for certain criteria are described as having "been raised from understanding to ability" (NAAB 2009, 45). The distinction of this language is important for three reasons. First, it officially connotes the value of particular modes of learning, and by extension modes of thinking. Second, by association, it assigns value to specific curricular areas. Third, the distinction between valuing the "ability" to apply certain skills and undervaluing the "understanding" certain concepts prescribes a spirit that effects the way curricula are designed and educators interact with students.

We assert the institutional position that values "ability" or proficiency in objectively measured criteria over "understanding" of issues is the source of and protector of the conditions that suppress more complex and inclusive approaches to architectural scholarship. Unfortunately, deeper insight into the "understanding" criteria does not appear to be the thrust of the 2013 conference to reevaluate the Accreditation Conditions document. A Framework document lays out the issues confronting higher education today such as: commodification of education, value-based demand for higher graduation rates and positive employment prospects (NAAB 2013, 2). As a result the "New/Emerging Issues That Must Be Addressed in the 2014 Conditions" focus on student demographics and educational backgrounds, new delivery models such as distance learning, and areas that can be directly linked to employment viability such as building sciences, emerging visualization skills, and achievement in comprehensive design. The governmental and capitalistic imperative of these goals, and the tone of their description clearly illustrates a deepening introversion of the institution with a focus on its own legitimacy.

Although the practice world sets the standards for desirable skills in prospective hires from architecture programs, the academic world sets the standard for the ideas and world-views graduating students. In contemporary academics, measures such as NAAB's Accreditation 
Conditions matter tremendously to the types of curricula present in schools. But more than that, the spirit inherent in the values of the measure matters. The spirit of the Accreditation Conditions preferences skill building over the development and expansion of knowledge. Although the practitioners who drafted the Conditions must certainly know better, this spirit belies the reality that architecture is an open-ended and often contradictory pursuit requiring subtle shades of understanding and cultural awareness. Relative to NAAB, a more assertive charge must be lead from within institutions who seek to change their own relationships with the world around them. As Crysler illustrated, the publication of architectural research has a large role in establishing the spirit of those relationships. Consequently, we feel that increased awareness of the inclusive priorities of qualitative research in the educational environment would help bring these criteria further into the spotlight to meet the evolving needs of the profession.

\subsection{The role current qualitative research methods play in excluding additional voices from architectural discourse}

Qualitative research does exist in academic architectural scholarship. However, it is rare, and its foundational principles differ significantly from its application in the social sciences. Where qualitative research satisfies an ontological and social imperative in the social sciences, its translation into architecture has largely shed any advocacy underpinnings. We find its application, however sparse, is often as insular and exclusionary as the scholarship discussed in section 1.2. ${ }^{1}$

Groat and Wang's compendium Architectural Research Methods is the seminal contemporary text for academic scholarship in architecture. It establishes baseline parameters and frameworks for: interpretivehistorical research, qualitative research, correlational research, experimental and quasi-experimental research, simulation and modeling research, logical argumentation, case studies and combined strategies. Using a single volume to comprehensively address the research methods "available and applicable to the diverse array of topics germane to architectural research" (Groat \& Wang, 3) restrains the authors from taking strong positions on the ethical imperatives that ground each method. This high-level distance is made clear in their chapter "Theory in Relation to Method" that "avoid(s) an explicit focus upon theories of just one discipline. Rather it seeks to outline what it means to theorize as such, independent of what is being theorized about" (Groat \& Wang, 74).

This either-or approach is maintained in the chapters on specific research methods. The focus on the method's functionality is at the expense of in-depth presentations of underlying theory. Unfortunately, qualitative research methods in particular are inextricable from the attendant ethical

1.For instance, the 2013 ARCC conference proceedings contained three papers out of eighty-eight that used some form of qualitative methods. Two of these three papers focused on the voices of other architects rather than additional voices outside the field (Jarrett, et al). and philosophical imperatives associated with their social science origins. The methods emerged from those imperatives. These imperatives exist in architecture as well. Groat and Wang's broad stance is useful to cover the territory they have prospected, but neglects the specific value architecture could find in qualitative research, and its deep congruence with the field. At the same time, its superficiality diffuses the urgency to increase qualitative methods in architectural scholarship.

To understand more of this context and why qualitative research is ethically relevant to architecture one must instead go elsewhere to reframe the cited literature in its field of origin, the social sciences. As the primary text framing research methods for architectural students, Groat and Wang's avoidance of philosophical underpinnings cannot be overlooked. Such avoidance provides greater grounds for concern over NAAB's privileging of ability over more thorough and rich understanding. Architectural research is presented as an extension of the architect's project of mastering conditions and providing correct answers.

Amidst their survey of qualitative research Groat and Wang present several example studies in architecture. Two in particular are given significant coverage and stand together for their subject matter: "Voices for Change in Architectural Education" (Groat \& Ahrentzen 1997) and Architecture: A Story of Practice (Cuff 1992). Both are qualitative studies utilizing the voices of architects. It is not noteworthy for architects to scrutinize their own profession. But for these to be the two foundational examples of qualitative research in architecture humorously ratifies the presupposition of this article: in scholarly circles, whose 'additional voices' are architects most willing to listen to? Other architects! This trend was further confirmed by the character of qualitative studies appearing in the premier journal of architectural education, the Journal of Architectural Education. $^{2}$

Groat and Wang do provide a couple of case studies in which the subject voices of the qualitative research are from outside the field of architecture. One, also by Ahrentzen, "A Place of Peace, Prospect, and a P.C." is a qualitative study of people who work from home. The other, Clare Cooper Marcus's House as Mirror of Self, focuses on precognitive realities of "house-self dynamic" through inhabitants' oral conversations with the house itself and through drawings and graphic communications. However, in keeping with the nature of their survey they do not distinguish what added value these welcome extra-disciplinary voices might have in relation to the intra-disciplinary examples.

Where Groat and Wang miss, their colleague, Ahrentzen, who is in fact a social ecologist and educator, fills in the ethical imperative for additional voices in architecture in terms of feminism's basic societal goals and how

2. Articles on the power dynamics of architectural juries (Webster, 21-27), gender and ethnicity bias in architectural curricula (Groat \& Ahrentzen, 1996), and the identity struggles of architects practicing in client-situated practices (Schermer). 
they might enter into the architectural discourse: "Looking at the social context shifts analysis from abstract and binary differences to the social relations and contexts in which multiple differences are constructed and given meaning [emphasis added]" (Ahrentzen 1996, 93-94).

\subsection{THE IMPORTANCE OF ADDITIONAL VOICES TO THE PRACTICE OF ARCHITECTURE}

\subsection{The profession's implicit call for additional voices in architectural discourse}

Of the two central exemplars of qualitative research in Groat and Wang's book, Dana Cuff's is the more significant and widely known of the two studies. Though focused on the voices of other architects, its thesis is more in keeping with the complex and inclusive ethos of qualitative research both methodologically and in its position on the practice of architecture. Cuff describes her work as an ethnography based primarily on extensive interviews and field observations. Excerpts of these have a prominent role in the vocal texture of the book. Cuff's intent, hypothesis, and conclusion is to denude the mystique that architecture is the domain of the isolated hero, the impression that architects, in their artist-like studios, worked in relative isolation, making drawings of buildings... from Howard Roark, hero of Ayn Rand's novel "The Fountainhead", who pursues at all costs his personal vision in the face of society's mediocrity (Cuff, 1).

What she found, and what she wanted to demonstrate, was a highly social practice, based on compromise, problem-solving, iterative thinking, and importantly, a shared culture. This is the optimistic antithesis of our above criticisms. It is the actuality of the profession that is misrepresented by the institutional voice of architectural scholarship. It is a truth best laid bare through the deep, immersive application of qualitative research.

The acceptance of qualitative analysis faced obstacles from positivists in the social sciences. Because of the diffusion of the scholar's voice that counters the mythology of architect as singular hero, its wholehearted acceptance in the conventions of architectural research will not be without detractors. It should be no great leap to see the value of more inclusiveness from the institutional nexus and outward into the profession. Perhaps the shift requires an admission on the part of academics to what Cuff illustrates their professional counterparts have already had to learn about the myths of homogeneity and univocality in the design process. The qualitative method is invaluable to readers in an academic setting for the way its complexity and contradictory voices demythify the powerful singular voice in architecture. Within the field, architects recognize that the production that "the production of places is a social process" (Cuff, 248). This quality is important for the profession in general to publicly bolster in the future.

\subsection{Why are additional voices valuable?}

The attitude implicit in architectural discourse is that untrained individuals cannot understand the complex interrelations between architecture and its cultural, economic, and material contexts. A countering perspective has been described in detail by Black feminist thinker Patricia Hill Collins. She presents two prevailing positions: that subordinate groups identify with their oppressors and therefore have no personal perspective on their identities, and that subordinate groups are less human and not capable of constructing articulating their own identities. However, in their everyday acts of resistance:

Black women's political and economic status provides them with a distinctive set of experiences that offers a different view of material reality than that available to other groups... these experiences stimulate a distinctive Black feminist consciousness concerning that material reality. In brief, a subordinate group not only experiences a different reality than a group that rules, but a subordinate group may interpret that reality differently than a dominant group. (Collins, 747)

Although Collins' position emerges from a very specific area of the social sciences, as a structural view of power relationships and silencing behaviors, it is applicable to other power dynamics. Consider by extrapolation all of the unique standpoints on architecture from all groups and individuals to which scholars are willfully deaf. By refusing to acknowledge the validity of these perspectives, of this consciousness, architectural discourse isolates itself from the substance of its inquiries: the role of architecture in society.

As a service industry, architecture depends on the needs and predilections of clients, and on the demands and perceptions of the public. At the same time, architects hold fast to the hermetic mysteries of inspiration that similarly characterize advances in the other four of the five arts. There is a sense that the public perception of architecture is somehow less relevant than the meanings ascribed by those in the profession. This conflicted identity may be a key factor in architectural scholarship's reluctance to break the fourth wall and employ alternative research methods that introduce additional, untrained voices.

\subsection{The American Institute of Architects' explicit call for additional voices in architectural discourse \\ Where NAAB strives for the legitimacy, or outright survival, of academic institutions of architecture, the goals of the profession itself express a desire to shift the tone and scope of practice to resonates more with Collins' attention to 'subordinate' groups. The published goals of the AIA give insight into the intended role of architects in the public realm. When compared to NAAB's Accreditation Conditions, the AIA's goals reveal an internal struggle for the identity of the profession.}


The AIA both lobbies for architects in the public sphere and endeavors to shape the dialog and public image of the profession. Membership does not oblige a practitioner to follow the optimistic policies and positions put forth by the AIA. In fact, the popularity ${ }^{3}$ of membership and the ubiquity of architectural blight on the American landscape nearly guarantees that the damage is being done by AIA members. Nonetheless, its basic tenets, developed by practitioners, can be seen as a barometer of the field's aspirations. In June, 2013 the AIA's Board of Directors issued an updated draft of their Directory of Public Policies and Position Statements. Leading off the document, the AIA's meta-policy blankets all subsequent goals under the imperative of architecture as a social agent. It states that: "architecture profoundly affects people. The work of architects is essential to human well being, and architects must embrace their ethical obligation to uphold this public trust" (AIA 2013, 4). We believe, whether transparently disingenuous or genuinely optimistic, a reading of the spirit of these goals is most pertinent. This spirit sets the stage for more quantifiable steps forward.

The meta-policy alone would be a significant catalyst to find new, more suitable ways of understanding the impact of architecture on the public but the document goes on to develop a finer grain demand. The third section of the document, 'The World' (following 'The Architect' and 'The Practice'), establishes a scope of goals that encourages the profession to better serving the public by ethically improving the quality of the world. Of the three sections, this most specifically ties back to the meta-policy. Under this heading are three subsections: 'Architects Collaborate', 'Architectural Design Matters', and 'Architects are Environmentally Responsible'. We will focus on the first two subsections here.

The 'Architects Collaborate' section discusses not only the value of interdisciplinary collaboration but the value of what could be described as multi-culturalism or diversity in the design process. The AIA encourages collaboration with, and inclusion of, people "who bring diverse experiences, views, and needs into the design process" (AIA $2013,13)$. Where traditional collaboration is often seen as a vehicle for introducing other extra-professional skill sets into the design process for technical, formal, or civic development, the AIA's call resounds more for rich personal and cultural inclusion, more human understanding. The document goes on to highlight "civil rights" and "diversity" as two crucial reasons for and products of this type of inclusive collaboration (AIA 2013, 13). It is noted that these principles are dedicated to "enhancing [...] the quality of life in our communities" (AIA 2013, 13). This highlights an interdependence of practice and public life as well as a need for more robust feedback loops and frameworks. But it also indicates the need for a systematic change from the profession's inaccessibility to the public.

3.In 2012 the AIA published that 81,000 of the 105,596 registered architects, or 76.7\%, were members (AIA 2012).
The 'Architectural Design Matters' section details the role of design in the AIA's intention for enhanced quality of life. The subheadings of this section are: 'accessible environment', 'housing', 'livable communities', 'historic preservation', and 'design excellence in public projects'. These categories call for architects to "advocate for responsible design that results in beautiful and healthy places that respect and accommodate society's diverse cultures and needs" (AIA 2013, 14). The juxtaposition of such broad aspirations as accessibility, housing, and livable communities with the murkier subjective waters of beauty and the accommodation of diverse cultures and needs illustrates the necessity to connect the collective with the specific and complex needs of the individual.

The two positions developed in these sections - the importance of collaboration and the value of good design - would both benefit from a stronger understanding of the complex nature of the social understanding, perception, and use of architecture. Most of the previously discussed NAAB criteria that are directly linked to the AIA's goals of "human wellbeing" and "public trust" (AIA 2013, 4) are given short shrift with the less rigorous "understanding" level of achievement. NAAB's focus for the future is invested in the viability and value of architectural education in the contemporary educational market, less so on what social and societal competencies young practitioners will have as they enter the field. This is in contradiction to the stated goals of the AIA for architecture's role in the public realm. How can the connection of society and the built world be strengthened in a way that is informed by real findings rather than the detached, self-serving vision of the architect?

The societal and social aspects of architecture, along with the diversity that the AIA hopes to cultivate and approach, require a more difficult and inexact approach. It also requires a slower, more systemic approach to shaping the identity of the profession. The more expansive and complex findings of qualitative research are one significant way to develop this knowledge. Additionally, the shift in tone from architect-centered to public-centered world-views that the social science models of qualitative research could introduce to architectural education is necessary to the transition of the profession's identity.

\subsection{QUALITATIVE RESEARCH}

\subsection{Qualitative research methods in the social sciences}

Educational psychologist and expert in research methodologies John W. Creswell defines qualitative research as beginning "with assumptions, a worldview, the possible use of a theoretical lens, and the study of research problems inquiring into the meaning individuals of groups ascribe to a social or human problem" (Creswell, 37). To give form to this method, Creswell stipulates several common characteristics of qualitative research: natural setting, researcher as key instrument, multiple sources of data, inductive data analysis, participants' meanings, emergent design, theoretical lens, interpretive inquiry, and holistic account (Creswell, 3739). For our purposes we will describe a few relevant characteristics 
in slightly more detail. By natural setting, Creswell asserts that data collection is done "in the field at the site where participants' experience the issue or problem under study" (Creswell, 37). By multiple sources of data, Creswell indicates that qualitative research uses heterogeneous forms "such as interviews, observations, and documents" (Creswell, 38). Great value is placed on participants' meanings. Creswell emphasizes that "in the entire qualitative research process, the researchers keep a focus on learning the meaning the participants hold about the problem or issue, not the meaning that the researchers bring to the research or writers from the literature" (Creswell, 39). These characteristics are all pertinent to architecture, being a site or setting itself, impacting multiple spheres of influence, and subject to vastly different interpretations and experiences.

Key to this strain of qualitative research is the constructionist epistemology. Social scientist, Michael Crotty provides a useful definition of constructionism:

It is the view that all knowledge, and therefore all meaningful reality as such, is contingent upon human practices, being constructed in and out of interaction between human beings and their world, and developed and transmitted within an essentially social context (Crotty, 42).

Constructionism does not imply unfettered subjectivity. Crotty reminds us that constructionism must therefore take "the object very seriously" (Crotty, 48). There must be a level of exactitude involved that is implicit in careful collation of methodology and rigorous use of data.

Creswell goes on to characterize subjects that would benefit from qualitative research as meeting eight loose criteria. We have reorganized them in order of their pertinence to the project of change described in this paper. First is the desire to empower individuals through sharing their stories, hearing their voices, and minimizing power relationships. Second is the study of a group in order to hear their silenced voices. Third is the belief that the context is inseparable from what is said. Fourth is the need for a complex and detailed understanding of an issue. Fifth is the usefulness of following up more formal studies to provide broader foundations for the mechanics of causal theories. Sixth is to introduce natural complexity to oversimplified theories. Seventh is the desire to write in a more inclusive, literary style, the eschew the institutonal voice. Finally, the eighth criterion is that qualitative research is used when formal and quantitative analyses are not congruent with the nature of the issue (Creswell, 40).

\subsection{More effective application of qualitative research to architecture} Qualitative research is not a panacea to the insular attitudes of the profession. However, it can be a more productive participant in changing those attitudes. In the social sciences it has served as a conduit to introduce the voices of the population into a professional dialog that had always been about them, but did not include them. Its increasing popularity over the last few decades has coincided with significant advances in addressing the needs of disenfranchised populations. Although there may be no correlation, at the very least scholarship is tracking with the trends of society. The same cannot be said for architecture. Where even the great proponent of inherent architectural meaning, John Ruskin, asserted that "not until a building has assumed this character... hallowed by the deeds of man, till its walls have been witness of suffering [that it] can be gifted with so much as these possess, of language and of life" (Ruskin, 234), it is time for architectural scholarship to turn its lens, and ear, outward to the voices of those people.

The formal characteristics and topical criteria of qualitative research inherently fit architectural subjects. The theoretical perspectives that establish much of contemporary architectural discourse, such as phenomenology, critical inquiry, and postmodernism, are methodologically congruent with qualitative research. However, as we have seen, qualitative research in architecture primarily focuses inward on the profession rather than on its external social and systemic effects. Qualitative research in architecture could effectively address ways in which its inhabitants construct and perceive aspects of its interconnection with its own fabric, with the oeuvre of the designer, other works of architecture, further afield manifestations of culture, historical conditions, social conditions, functions of perception, and so on.

Creswell describes five qualitative approaches, of which we will look at two, narrative research and phenomenological research, and propose potential areas of application. The other three, grounded theory research, ethnographic research, and case study research, would certainly also be applicable.

Narrative research focuses on being a singular and deep forum for personal experience. The sample size of narrative research is limited to one or two individuals. Data gathered takes the form of life-stories and related individual biographical experiences with an interpretive interest in causality (Creswell, 54). In relation to architectural research this limited scale of inquiry and broad scope of temporality might be suited for gross scale analyses such as urban or cultural fabrics and typologies. Individual perspectives are often lost in data driven urban analysis. Conversely, more intimate and smaller scale, limited access settings like dwellings might profit from narrative research. Objective histories of exceptional domestic settings eliminate the well-worn textures of life that the rhetoric of qualitative research can draw out.

Phenomenological research "describes the meaning for several individuals of their lived experiences of a concept or phenomenon" (Creswell, 57). Phenomenology is a theoretical perspective already applied in scholarly architectural research as a philosophical lens as opposed to a methodology for collecting data. This approach's broader participant sample is balanced against the goal of looking for shared 
meaning and experience. Phenomenological research is grounded in the belief that the reality of an object is inextricably linked to one's consciousness of it (Creswell, 59). This seems suited to the physicality of architecture and particularly to singular works that are able to be experienced in a number of different ways. It may also be applicable to a particular aspect of architecture across a variety of types, or of multiple instances of a particular type. Because of its focus on common experiences, phenomenological qualitative research provides a deep foundation to developing practices or policies related in a field (Creswell, $60)$.

Within the variety of approaches to qualitative research are a wide range of data collection methods. In addition to those described above, methods such as unstructured interviews, life histories, and participantguided tours or shadowing, are applicable to architectural research. These methods capture two qualities that are not present in institutional scholarly research. First, their openness allows for the extraneous, the noise, to become part of the complex meaning of the work. This is more congruent with the actuality of architecture. Second, they rely heavily on a tangible relationship with the architectural object. Qualitative research methods and findings are inseparable from the realities of the built environment.

Revisiting the initial provocation of who has the right to speak for a building, serious consideration of participants is crucial to qualitative research in architecture. Like any practice involving a heterogeneous collection of individuals, there are many contingencies at play. Qualitative studies depend on effective data collection. The diversity of participants is important but should be tailored to the specific approach being used. For example, a phenomenological study may use participants from diverse sites, but should share enough common characteristics to provide a level field for comparing their experiences. Building rapport is also a crucial component of working with participants. Creswell acknowledges that because of a researcher's identity, participants may be uncomfortable relating information to them (Creswell, 139). This may be particularly true for architecture. Where the public sees architects as distant creative figures, they may feel silenced by the perceived power imbalance; at the same time, they may relish finally getting to set the record straight. This can all be addressed by the attitude of the researcher. The researcher should make every effort to demonstrate the value of the participant's insights. Taking a cue from feminist pedagogy, the researcher should acknowledge the participant as an active student of the built world since childhood. Though no qualitative study will have the torrent of data that a quantitative study does, it is always possible to find people interested in being heard. All people have stories to tell. The investment of citizens who are affected by planning and zoning decisions and the willingness of building occupants to voice their opinions, whether to their peers or to the media, are a good barometer to level of enthusiasm that might be found in data collection.

\subsection{Areas of qualitative inquiry in architecture}

Society and Space, although not definitively an architectural journal, presents a number of qualitative studies that overlap with architecture. These provide insight into possible avenues of inquiry. For example, an article exploring constructions of femininity in the Russian penal system includes fieldwork and qualitative data gathered from interviews with prison staff and from media sources to give deeper understanding into the intensely personal constructs of gender in relation to the strictures of the architectural type (Moran, et al 2009). Another article analyzing the conditions of gentrification in Edinburgh, Scotland uses interviews with new residents in gentrifying neighborhoods to provide representative texture to the language and direct insight into motivations, which often deviated from quantitative data also gathered (Bondi 1999). This journal, Enquiry, also has a more positive history relative to its peers of publishing works of qualitative research. One exemplary article utilized a diverse palette of methods including "structured interviews, location mapping, photo-documentation, architectural inventories, place-centered behavioral mapping, and focused observations... [and] experiential collage" (Keddy, 1 ) to gain insight into the spatial conditions of the nursing workplace.

Creswell's 'lack of fit' criteria is useful for discovering other subject matter that might benefit from qualitative inquiry. The perception of success or failure of Boston City Hall by Kallmann, McKinnell \& Knowles in David Monteyne's article "Boston City Hall and a History of Reception" (Monteyne 2011) is a ripe topic. In order to more sensitively assess the divide between professional adulation and public dissent, Monteyne draws on reception theory. Reception theory is a constructionist position that places the source of meaning in the audience. The article utilizes a scattering of cited quotations related to public perception of the city hall amidst a preponderance of professional and institutional positioning. Even the cited quotes from the public are limited to single word fragments that fit the author's narrative. Though touting a method steeped with interest in public perception, Monteyne opens his section on the "Unschooled Reception" with an extended quote from venerable architectural historian Sybil Maholy-Nagy. Monteyne's article represents a key missed opportunity to introduce significant content of additional voices in relation to what is regarded as one of the most famous examples of ferocious public sentiment regarding architecture in the United States. He indicates that the qualitative method was an important aspect of his understanding of the building but primarily presented opinions of architects in their own voice and filtered the voice of the public through his own or through that of other publications.

Although certainly more such work exists, the greatest break with convention and the most inclusive work in this survey is artist Imogen Ward-Konao's "Anything Red Doesn't Come to the House" (WardKanao 2000). This text is described as a "visual diary" of the author's apprenticeship to a Ghanaian painter, Leticia Azuru, in a section 
of the book described as including "a more elastic interpretation of architecture" (Lokko, 279). Including a wide range of photographic materials documenting her experience, Ward-Konao also includes a very lengthy and detailed transcription of a conversation with her mentor. This interview contains not only what the author set out to glean from the encounter but information that does not support any particular agenda. In fact, its unabridged inclusion of chit chat, comments on clothing, food, and customs develops a texture without a fixed meaning. None of this is directly applicable to painting. However, without it, the meaning of Azuru's painting practice would be monolithic, abstract, and distant.

There is no shortage of fodder for qualitative research in architecture. We do not presume to limit the possible scopes. Crysler wonders "what would happen, for example, if the writers at Assemblage employed the methods of the "post-occupancy" study to determine whether the rhizomatic claims of the Deleuzian "blob" architecture produced any of its putative effects ?"(Crysler, 200). Indeed, we hope to have illustrated a necessity for the richness of information that can come from these types of inquiries in all arenas.

\section{CONCLUSION}

Michael Crotty jokes that "not too many of us embark on a piece of social research with epistemology as our starting point... We typically start with a real-life issue that needs to be addressed... a question that needs to be answered" (Crotty, 13). Real-world problems of health, access to services, environmental fragility, and quality of life all hinge on the perspectives and interests of the non-architect public. Based on the question, sometimes qualitative methods are of value, sometimes not. However, its extremely limited application in architectural scholarship is startling. Qualitative research is an invaluable tool for exploring the complexities and ambiguities of those perspectives and interests, not what architects believe they should be. The desire to incorporate additional voices into the discourse of architecture is already strong. The AIA's noble goal of increasing social outreach and more inclusive design processes is central to this charge. This must start in the culture of education. An emphasis on qualitative research and a celebration of its roots in constructivism and advocacy are an essential component of this shift.

Sherry Ahrentzen places the responsibility for change squarely in the discourse of academic institutions, calling for a deeper look and reconfiguration of "education as well as indoctrination of the professional and non-professional involved in placemaking" (Ahrentzen 1996, 95). She emphasizes the importance of social communities and consciousnessraising groups as a means to influence institutional meaning in society. The question is: how is the design profession currently fostering these communities? How is the design profession giving these communities a voice? We can start by recognizing their role in our profession, and by allowing them to constructively participate in the dialogue that materially shapes their world.

\section{REFERENCES}

Ahrentzen, Sherry. 1996. "The F Word in Architecture: Feminist Analyses in/of/for Architecture." Reconstructing Architecture. ed. Thomas Dutton and Lian Hurst Mann. University of Minnesota Press: Minneapolis, MN.

Alexander, Zeynep Çelik. Allais, Lucia. de Bruyn, Eric C.H. Coleman, Gabriella. Elcott, Noam M. Harwood, John. Hunter, Matthew C. 2000. "About Grey Room..." Grey Room. No. 1.

Alloway, Lawrence. 2006. "The Critic and the Visual Arts." Imagining the Present: Context, Content, and the Role of the Critic. ed. Richard Kalina. Routledge: London, England.

American Institute of Architects. 2012. Press Release. Retrieved from http://www.aia.org/press/AIAS077761.

American Institute of Architects. 2013. Directory of Public Policies and Position Statements. ed. The Board of Directors. American Institute of Architects: New York, NY.

Bondi, Liz. 1999. "Gender, Class, and Gentrification: Enriching the Debate." Society and Space. Vol. 17, No. 3. 261-282.

Collins, Patricia Hill. 1989. "The Social Construction of Black Feminist Thought." Signs, Vol. 14, No. 4, Common Grounds and Crossroads: Race, Ethnicity, and Class in Women's Lives. The University of Chicago Press: Chicago, IL.

Creswell, John W. 2007. Qualitative Inquiry \& Research Design: Choosing Among Five Approaches. Sage Publications: Thousand Oaks, CA.

Crotty, Michael. 1998. The Foundations of Social Research: Meaning and Perspective in the Research Process. Sage Publications: Thousand Oaks, CA.

Crysler, C. Greig. 2003. Writing Spaces: Discourses of Architecture, Urbanism, and the Built Environment. Routledge: New York, NY.

Cuff, Dana. 1992. Architecture: A Story of Practice. MIT Press: Cambridge, MA. 
Groat, Linda. Ahrentzen, Sherry. 1996. "Reconceptualizing Architectural Education for a More Diverse Future: Perceptions and Visions of Architecture Students." Journal of Architectural Education. Vol. 49, No.3, 166-183.

Groat, Linda. Ahrentzen, Sherry. 1997. "Voices for Change in Architectural Education." Journal of Architectural Education. Vol. 50, No.4, 271-285.

Groat, Linda. Wang, David. 2002. Architectural Research Methods. John Wiley \& Sons: New York, NY.

Jarrett, Chris. Kim, Kyoung-Hee. Senske, Nick. 2013. The Visibility of Research. University of North Carolina Charlotte: Charlotte, North Carolina.

Keddy, Karen. 2009. "New methods of researching healthcare facility users: the nursing workspace." Enquiry. Vol. 6, No. 2.

Lorde, Audre. 2007. "The Master's Tools Will Never Dismantle the Master's House." Sister Outsider. Ten Speed Press: New York, NY.

Monteyne, David. 2011. "Boston City Hall and a History of Reception." Journal of Architectural Education. Vol.65, No.1.

Moran, Dominique. Pallot, Judith. Piacentini, Laura. 2009. "Lipstick, Lace, and Longing: Constructions of Femininity Inside a Russian Prison." Society and Space, Vol. 27, No.4. 700-720.

National Architectural Accrediting Board. 2009. 2009 Conditions for Accreditation. National Architectural Accrediting Board: Washington, DC.

National Architectural Accrediting Board. 2013. Framework for ARC13. National Architectural Accrediting Board: Washington, DC.

Ruskin, John. 1903. The Seven Lamps of Architecture. George Allen: London.

Schermer, Brian. 2001. "Client-Situated Architectural Practice: Implications for Architectural Education." Journal of Architectural Education. Vol. 55, No.1, 31-42.

Ward-Konao, Imogen. 2000. "Anything Red Doesn't Come to the House." White Papers, Black Marks. ed. Lesley Naa Norle Lokko. University of Minnesota Press: Minneapolis, MN.

Webster, Helena. 2007. "The Analytics of Power: Re-presenting the Design Jury." Journal of Architectural Education. Vol. 60, No.3, 21-27. 